\title{
Experimental Testing of Composite Rings under Uniform External Hydrostatic Pressure
}

\author{
Lei $\mathrm{Fu}^{1}$ and A. M. Waas ${ }^{2}$ \\ Dept. of Aerospace Engineering, Unv. of Michigan, Ann Arbor, MI 48109-2118
}

\begin{abstract}
The results obtained from the experimental testing of hoop wound S-2 Glass/Epoxy and AS4/ PPS composite rings are presented here. In this study, the effects of different material system and thickness on failure are investigated. A custom, volume controlled pressurization set-up was designed and built for the tests. Initial imperfection in the ring specimens were measured prior to testing and the hoop modulus of the rings tested were measured and compared with Classical Lamination Theory predictions.
\end{abstract}

Results indicate that the failure mode is global ring buckling. The initial postbuckling behavior is stable for both S-2 Glass/Epoxy and AS4/PPS rings. The rings tested were elastic and no permanent deformation was observed. Out-of -plane twist buckling was observed in both the thick S-2 Glass/ Epoxy and AS4/PPS rings $(R / t<9.5)$. Mode three buckling was observed when the ring specimens were constrained by the sealing ring (rubber $\mathrm{O}$ ring) used in the experiment, however, mode two buckling was obtained when this constraint was removed, via a bladder type loading.

\section{Introduction}

The main aim of this investigation is the experimental determination of failure mode of composite

1. Graduate Student Research Assistant, Student Member AIAA.

2. Asst. Professor of Aerospace Engineering, Senior Member AIAA.

Copyright $($ C 1994 by Anthony M. Waas. Published by the American Institute of Aeronautics and Astronautics, Inc. with permission. rings. The motivation for this work stems from the wide variety of failure modes that composites exhibit when compared to their isotropic metal counterparts. Rings were chosen as the preferred geometry of the test specimens as there are many applications in pressure vessels and container technologies where composite rings or tubes are important structural members, and it is important that their failure behavior, is well understood.

Much work has been performed in the field on the experimental determination of the failure of thick composite rings and cylinders under external hydrostatic pressure [1][2][3][4]. Most of the work was concentrated on failure of the composite structure as a result of waviness in the constituting plies of the composite [1][2] and thus the composite rings and tubes tested were designed to fail below their buckling pressure. In the work that is presented, the effect of thickness and different material system on failure due to ring buckling is investigated.

A novel experimental set-up was designed to pressurize composite rings constructed of different thicknesses and different material systems up to a pressure of $5000 \mathrm{psi}$. The pressurization is either via a volume control or a displacement control setup. A volume control pressurization is desirable as the failure process could then be captured while in a pressure controlled test the failure will be catastrophic. The thickness of the ring specimens are chosen so that a series of rings ranging from a radius to thickness of 5, which is a very thick ring, to 27.5, which can be considered a very thin ring are tested. The ring specimens tested are constructed of two different kinds of material systems, S-2 Glass/Epoxy and AS4/PPS. 
Both a 2-D and a 1-D shear deformation initial post-buckling analysis has been completed [6]. Results indicated that the experimental buckling pressure is well modelled by the 2-D and 1-D theories and the initial post-buckling stability response to be stable.

\section{Pressure Test Set-up}

\section{Pressure Chamber}

The initial pressure chamber is constructed such that there is a clear quartz view port through which the response of the ring under test can be observed and recorded on film or video tape. The pressurizing hydraulic fluid is sealed from the ring specimen via O-Rings. It was found that with 70 durometer $\mathrm{O}$-rings that were used, that there was too much friction between the $\mathrm{O}$-ring and the quartz view plate. This friction caused the ring specimens to undergo mode 3 buckling rather than the mode 2 buckling that was predicted by theory.

Modifications were made to the chamber and a custom 70 durometer rubber bladder was designed and ordered. Further testing with the thinnest composite rings revealed that the rubber bladder was caught in the space between the quartz view plate and the ring specimens tested and this "door-stopper" effect (refer Figure 1) caused the ring to buckle into mode three as the motion of the ring is constrained. This "door-stopper" effect was finally removed when the chamber was modified to include a precision machined steel cover plate with a central hole that is slightly larger that the diameter of each individual ring tested and the quartz view port removed.

Different bladders with various durometers $(40,60,70$ and 90$)$ were experimented with and it was found from the pressure vs. strain gage reading curve that the pressure is successfully transferred from the hydraulic fluid to the ring for all bladders tested. Loading and unloading tests performed with the servo-feedback system also indicated that there is very little, if any, hysteresis between the loading and unloading curves, indicating that no work is lost due to the bladder. A small hand pump was utilized to initially inflate the rubber bladder prior to the pressurization process and the pressure chamber was flushed with a flushing pump for about $15 \mathrm{~min}$ utes prior to testing to remove any residual air in the chamber introduced during the installation of the composite ring specimen. Pressurization of the bladder without a specimen indicates that very little pressure is required to inflate the rubber bladder to large deformations. This indicates that the bladder is stretching like a membrane and not restricting the motion of the specimen.

\section{Pressurization Systems}

The pressurization of the composite ring specimens were accomplished by a volume controlled set-up. This is accomplished via (a) a servo-hydraulic feedback system and (b) a metering pump (refer Figure 2).

In the servo-hydraulic feedback system the pressure increase is achieved by having a master piston with a 6" diameter bore pushing on a slave piston with a 2" diameter bore. The motion of the master piston is controlled by a servo-hydraulic feedback system where the position of the piston is measure with a LVDT and this signal is fed into the servo-hydraulic feedback controller. The opening and closing of the servo valve is then controlled by the servo-hydraulic controller so as to match the signal from the LVDT with that from a ramp generator. The ramp generator dictates the motion of the master piston which in turn controls the pressurization process. The pressure is measured by a pressure transducer that is connected to the pressure chamber and rated to $5000 \mathrm{psi}$.

The servo-hydraulic set-up has the advantage of allowing control of the unloading of the rings as the piston can be made to move inwards or outwards (see Figure 3). Since a servo-hydraulic feedback system is utilized, the set-up can be easily modified to perform a pressure controlled test. Here the signal from the pressure transducer is utilized as the feedback signal and the pressurization rate is then prescribed.

The servo-hydraulic feedback system set-up is found to be adequate in volume control tests but it 
was found that the metering pump set-up produces more accurate pressure increases as the pressure builds up. With a volume control set-up the rate of decrease in volume is pre-defined, causing an initial exponential build up in pressure as the hydraulic fluid is almost incompressible. This produces, in the feedback control set-up and at high pressures, pressure increases that were large and thus the metering pump set-up (see Figure 4) was the set-up of choice when testing in the high pressure regime.

With the metering pump set-up, the pressure increase is accomplished via controlling the flow rate. In the present, this range was 1.9 to 160 milliliters per hour. The rate of pumping is changed by changing the stroke of the tiny piston in the pump and this can be performed during the test itself, thus providing the option of changing the flow rate in the middle of the experiment.

The disadvantage of using the metering pump for pressurization is that there is no way of unloading the rings gradually as the metering pump only pumps fluid one way. The reservoir of the metering pump set-up also had to be pressurized to about 20 psi as the hydraulic fluid is too viscous for the suction stroke of the pump.

The rubber bladder manufactured is a membrane with a $\mathrm{C}$ channel cross-section. The membrane is sealed by crushing the two flanges of the $C$ channel of the rubber membrane between the top and bottom pressure chamber plates and the pressure inlet plate (refer Figure 1 ). Initially a rubber $\mathrm{O}$ ring is utilized on the bottom pressure chamber plate between one of the $C$ flanges and the bottom plate, but this configuration is determined to cause leaks between the rubber flange and the pressure inlet plate at pressures above $3000 \mathrm{psi}$ and the O-ring was removed in later tests.

A safety check valve rated to $6000 \mathrm{psi}$ is also installed to the pressure chamber to prevent the pressure in the experiment from exceeding $6000 \mathrm{psi}$ and damaging the pump.

\section{Measuring Devices and Data Acquisition}

The data acquisition system consist of an IBM model 70 personal computer, the Keithley DAS-8 data acquisition card and the LabTech Notebook software. The analog channels are sampled at 1 hertz and the analog to digital conversion has a resolution of 12 bits. With this setting of the data acquisition system, the bit resolution on the strain gages is 24 micro-strains and the resolution on the analog channels is 4.88 millivolts. A sampling rate of 1 hertz was chosen.

The duration of the pressure test is video taped and later the video frames of the test specimen is captured and digitized with a F/X video facility. This enables us to identify the bifurcation mode in the tests that were performed with the quartz view port. Due to the resolution of the video capture system and the small amount of motion that was detected in the mode 2 buckling of the composite ring it was not possible to obtain the buckling mode information directly from the video images captured for tests performed at pressures above 3000 psi. This is because before the ring specimens could under go large deformations, the rubber bladder would have extruded from under the annular steel cover plate and burst.

A Philtec optical probe is utilized for the measurement of the radial displacement during the test. This provided a much better measurement of the radial contraction due to its high resolution and accuracy although this measuring device is only good at obtaining the radial displacement at one point on the ring.

The probe is custom designed to have a $90^{\circ}$ bend tip and a probe diameter of 0.180 inches thus allowing it to be placed in the pressure chamber with the quartz covering plate. The Philtec probe chosen is color compensated and the intensity of the ambient light in the laboratory is kept constant during the duration of the test so as not to affect the probe reading. The probe measuring tip is placed directly over the inner radius of the ring specimens which were painted white. The probe used is calibrated with the painted ring specimens prior to testing with the lighting conditions in the laboratory kept constant.

$120 \mathrm{ohm}$ strain gages were mounted on the inner radius of the composite ring prior to testing. The location of the strain gages were determined by 
initial imperfection measurements performed on the rings prior to testing. Initially, eight strain gages were utilized and these were mounted in the hoop direction on the inner radius of the rings tested (refer Figure 5). The main purpose of these gages was to indicate that the pressure is transformed uniformly to the ring specimen under test and to detect the onset of buckling.

The location of the strain gages are such that all of them reside on the anti-nodes of the mode 2 imperfections and this is determined from the imperfection data obtained for the ring prior to mounting the gages.

\section{Specimen Manufacturing and Preparation}

\section{Specimen Manufacturing}

Two types of ring specimens were tested. The S-2 Glass/Epoxy rings were cut from 12 inch hoop wound tubes while the AS4/PPS rings were cut from similar tubes obtained from a different supplier. The S-2 Glass/ Epoxy rings were fabricated with Owens Corning S-2 1250 Yield Glass Fiber Roving and Epon 828 Resin/Epoxy with AC-Methyl used as the hardener and BDMA as the accelerator while the AS4/PPS tubes were manufactured from Graphite reinforced PPS Thermoplastic. Due to the Thermoplastic tape width, the AS4/PPS tubes are not hoop wound but manufactured with the carbon fibers forming an angle of about 88 degrees with the tube axis while the S-2 Glass/Epoxy tubes were filament wound.

The composite rings are cut from the tubes in a water bath with a high speed lathe and diamond coated saws. The rings were cut to a height of 0.184 inches with a tolerance of 0.0005 inches. This was the initial design specification so as to ensure that the ring fits in the pressure chamber loosely with a small enough clearance between the specimen and the clear quartz plate so that the rubber bladder does not squeeze through under pressure. Since the tubes were manufactured by winding the composite around a mandrel which has a diameter of 2.7 inches with a tolerance of 0.001 inches, the inner diam- eter of the ring specimens is 2.7 inches with a tolerance of 0.001 inches.

Six tubes were manufactured with each of the two material system, with tube wall thicknesses of $0.05,0.10,0.15,0.20,0.25$ and 0.30 inches. The tolerance on the thickness of the tubes were within ten thousandths of an inch due to the manufacturing process. This lack of precision in the thickness tolerance is not a problem as the thickness variation of each ring specimen tested was measured to a tolerance of 0.001 inches before testing. This variation in thickness presents itself as an initial imperfection in the mean radius of the rings tested.

\section{Specimen Preparation}

Prior to pressure testing, the initial imperfection of the ring specimens were measured and strain gages mounted on the inner surface of the specimens.

The inner radius of the rings were assumed to be perfectly circular and the imperfection is measured on the outer radius with an optical non-contact probe. The ring specimen is mounted on a tapering mandrel which is rotated by a d.c. motor the motion of which is controlled by the voltage supplied (Figure 6). The Philtec optical probe is positioned with fixed clamps at a fixed position and the output from the optical probe is passed through a switch to the digital data acquisition system. The switch is turned on and off by a level on the rotating mandrel and the position at which the switch is turned on and off is marked on the ring specimen with a permanent marker. Since the switch is turned on and off every 360 degrees of rotation of the mandrel, the location of the imperfection reading is known

The imperfection data obtained by the data acquisition system is then input into a program written in Mathematica where the coefficient of the different Fourier modes are computed. The coefficient of the lower Fourier modes $(2 \theta, 3 \theta)$ are the ones of interest in the buckling analysis. From these Fourier modes, the location of the anti-nodes is determined. This helps in placing the radial 
displacement probe and strain gages for the detection of buckling to be most effective.

\section{Material Property Determination}

Since the hoop modulus of the ring specimens tested is needed to compare the experimental results with a proposed theoretical model, a way of determining the hoop modulus of the ring specimens is next described.

Three separate methods were derived to measure or calculate the hoop modulus. First, the hoop modulus was calculated with Classical Lamination Theory as both the lay-up and the material system information of the rings were provided by the manufacturers. However, since a margin of error nor tolerance on the specifications was not indicated in the information provided by the manufacturer, experimental values of the hoop moduli had to be obtained.

A 2-point loading device was constructed (Figure 7) and the hoop modulus was obtained from the pressure vs. diametric contraction plots. The results obtained through this test were found to be within $5 \%$ of the results obtained with Classical Lamination Theory if the rings tested were thin. Lastly, the hoop modulus was obtained from the initial pressure vs. strain readings from the actual pressure test. This result is also within $5 \%$ of the values obtained from the previous two methods thus indicating that a separate measurement of the hoop modulus is not critical as the hoop modulus can be obtained from the pressure test itself.

\section{Post processing of the test data}

The experiment is terminated when either the ring has undergone buckling or the rubber has been extruded from under the cover plate. Upon termination of the test, the ring specimen is removed from the pressure chamber and inspected for damage.

The data obtained with the data acquisition system is then transferred to a workstation where the data is post-processed and plots of pressure versus hoop strain gage readings are made [7].
The deformations as measured by the optical displacement probe are utilized in conjunction with the Southwell method to predict the buckling pressure of the rings [5][7]. Plots for all buckled ring specimens indicates a stable initial post buckling response (Figure 8 and 9).

\section{Results and Discussion}

The experimental result obtained with the quartz cover plate and the bladder indicated that the ring specimen has gone into mode 3 bifurcation. This is a result of the door-stopper effect of the rubber bladder and the result is as predicted by a one dimensional model where the door-stopper effect is modelled as a spring like layer that opposes the motion of the ring. The higher bifurcation load and the mode 3 bifurcation mode is also predicted by this door-stopper model.

With the modified pressure chamber set-up the quartz cover plate is removed and the ring specimen exposed to the outside. The rubber bladder is held under a steel cover plate and since the steel cover plate does not extend over the top of the composite ring, the door-stopper effect is eliminated. It was found from this test configuration that the ring exhibits mode 2 buckling. Both the mode and load is correctly predicted by the numerous theoretical models that exists in the literature and by a two dimensional model that has been formulated and repeated elsewhere [6].

It must be noted that, as the ring thickness increases $(R / t<10)$, the buckling mode gravitated towards, what could be best described as twist buckling [8], involving out of plane deformation. To prevent this, the rings were held in place at four points (spaced $90^{\circ}$ apart) by thumb screws that were mounted onto a fixture that was attached to the bladder cover plate. This anti-twist device ensures planar ring buckling.

The initial postbuckling behavior is found to be stable and this is most evident in the case of the thin S-2 Glass/Epoxy and AS4/PPS rings. Strain gage readings obtained from the experiment indicates mode 2 buckling as strain gages placed $180^{\circ}$ apart behave similarly during loading. 
From the strain gage readings, a clear indication of the buckling load of the ring specimen under test (refer to Figure 8 and 9) is obtained. The modified non constraining pressure chamber does not allow for large deformation of the rings tested. Thus, the pressurization process was stopped immediately proceeding ring buckling. This is especially critical for the thick rings as their buckling pressure is very high. Once the thick rings buckle, the unconstrained bladder extrudes and bursts, being not able to contain the high pressure.

This method of obtaining the buckling load is based on the assumption that the strain readings taken on the inner radius of the ring at $90^{\circ}$ apart depart differently from a uniform state due to the ring bending associated with the onset of buckling. Also, if the strain gages were accidentally mounted on the location of the anti-nodes of the bifurcated mode, the readings of the strain gages will not be as sensitive and the detection of bifurcation may be delayed.

The readings obtained from the optical probe is ideal for indicating the buckling load of the rings tested (refer to Figure 10). Southwell plots of the experimental data obtained from the optical displacement probe were also analyzed. The buckling load obtained this way was found to be within $10 \%$ of the values obtained from the pressure vs. strain gage plots (Figure 11).

Similar plots for the thicker S-2 Glass/Epoxy and AS4/PPS rings are presented elsewhere [7], and will not be repeated here.

\section{Conclusion}

The response of S-2 Glass/Epoxy and AS4/PPS composite rings of various thickness, subjected to external pressure has been studied. The ring specimens tested failed by global ring buckling, prior to any material failure.

Initial test configuration with the pressurizing rubber O-ring acting as a "door-stopper" produced in-plane buckling modes that is mode 3 in nature. This mode 3 bifurcation is predicted by a constrained ring buckling analysis, whose details are presented elsewhere [7]. Upon removing this "door-stopper" effect from the experiment, the ring specimens exhibited mode 2 buckling.

The pressurization was volume controlled and it was observed from the experiment that the initial postbuckling behavior of the composite rings tested is stable. A 2-D initial postbuckling analysis was performed [6] and the initial postbuckling coefficient is found to be positive and almost neutrally stable. This result is also indicated by the experiments where the pressure vs. radial displacement plots were almost horizontal in the postbuckling regime (Figure 10).

\section{Acknowledgments}

The authors are grateful for the financial support of the ONR Mechanics Division with Dr. Yapa D. S. Rajapakse as the scientific officer. We also thank Jackson Flexible Products for the assistance in preparing the rubber bladder and Automated Dynamics for providing the AS4/PPS composite tubes.

\section{References}

1 Abdallah, M. G., Gascoigne, H. E., Cairns, D. S., and Patton, K. B., 1990, "Measurement of Deformation in Thick Laminated Composite Rings subjected to External Pressure", Proceedings of the 1990 SEM Spring Conference on Experimental Mechanics, pp. 719-724.

2 Abdallah, M. G., Gascoigne, H. E. and Cairns, D. S., 1991, "Experimental Investigation of Thick-Walled Graphite/Epoxy Composite Ring under External Hydrostatic Compressive Loading", Proceedings of the 1991 SEM Spring Conference on Experimental Mechanics, pp. 626-631.

3 Chaudhuri, Reaz A., 1991, "Prediction of the Compressive Strength of Thick-Section Advanced Composite Laminates", Journal of Composite Materials, Vol. 25, pp. 1244-1277.

4 Su, K. B., 1992 "Experimental Design and Investigation of the Compressive Behavior of Carbon/Epoxy and Glass/Epoxy Rings with and without Delamination Defects", American Society for Composites 7th Technical Conference on Composite Materials.

5 H. G. Allen and P. S. Bulson, "Background to Buckling", Text, McGraw-Hill, pp. 83-85. 
6 L. Fu and A. M. Waas, 1993, "Initial Post Buckling Behavior of Thick Rings under Uniform External Hydrostatic Pressure", submitted to the Journal of Applied Mechanics.

7 Lei Fu, 1994, "Response and Failure of Thick Composite Rings Subjected to Uniform External Hydrostatic Pressure or Contraction", Ph. D. Thesis, in preparation, University of Michigan, Ann Arbor, MI 48109.

8 Thein Wah, 1967, "Buckling of Thin Circular Rings under Uniform Pressure", International Journal Solids Structures, Vol. 3, pp. 967-974.
Figure 2. Picture showing Metering Pump Pressure Testing Setup.

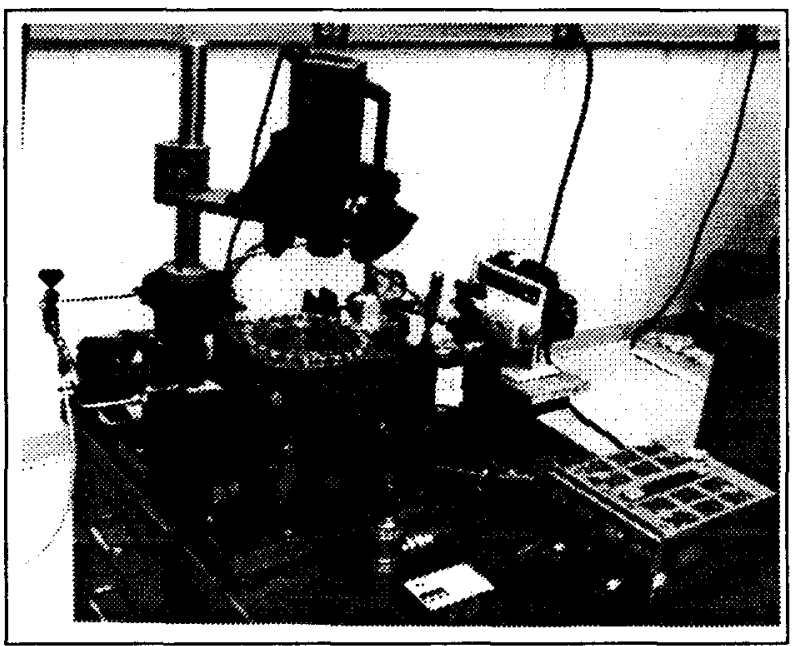

Figure 3. Block Diagram showing Servo-hydraulic Feedback Loading System

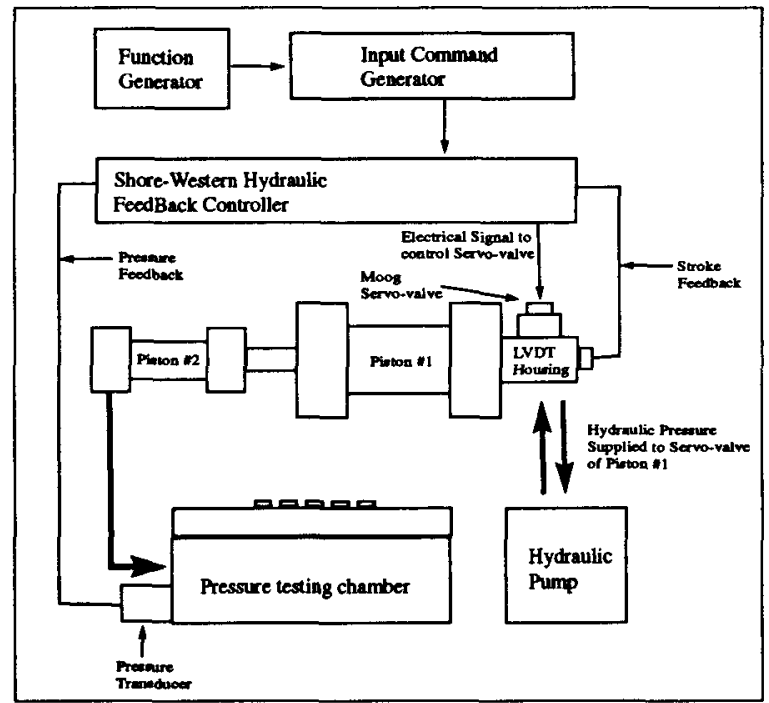


Figure 4. Block Diagram showing LDC Metering Pump Pressurization System.

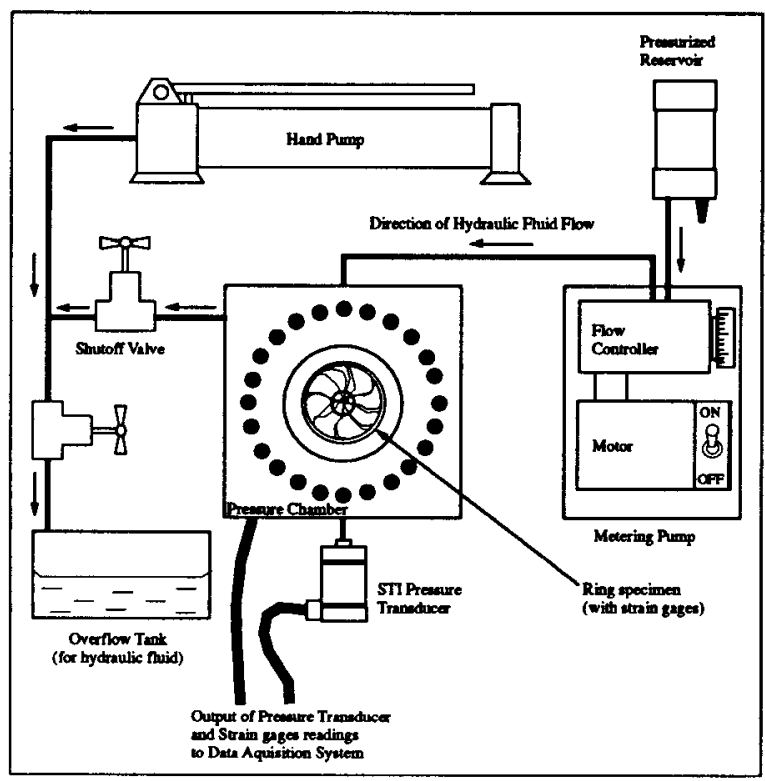

Figure 5. Strain Gage Locations.

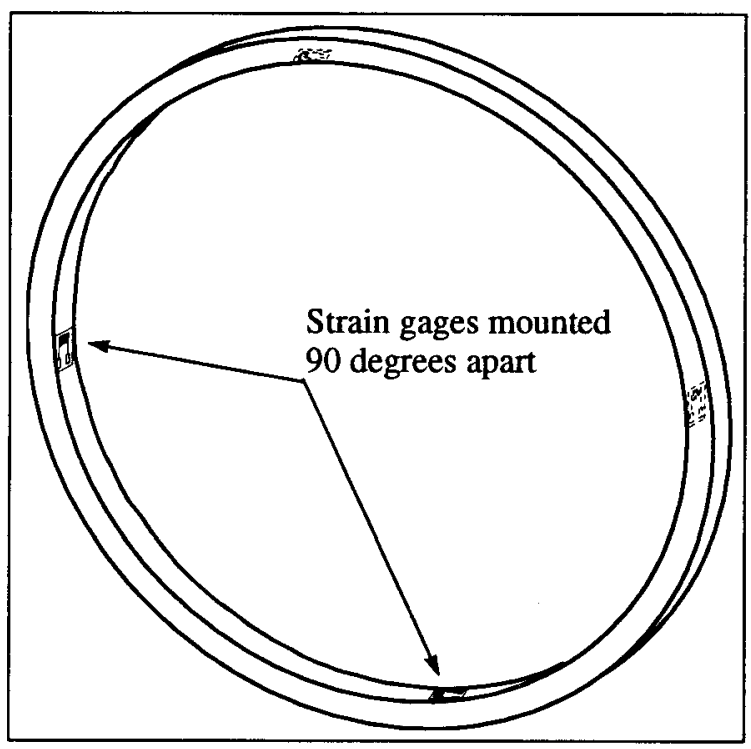

Figure 6. Picture of Initial Imperfection Measurement Setup.

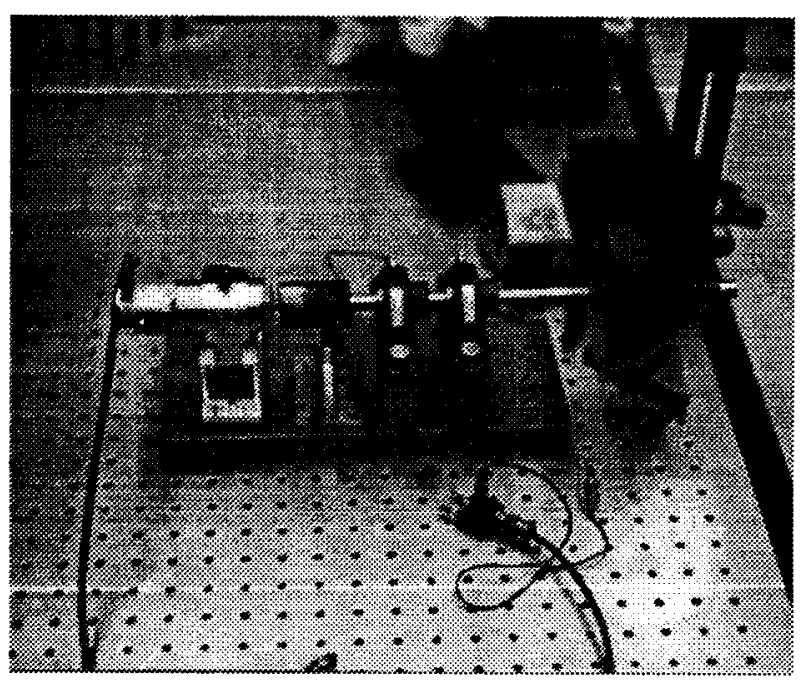

Figure 7. 2-Point Loading Testing Set-up.

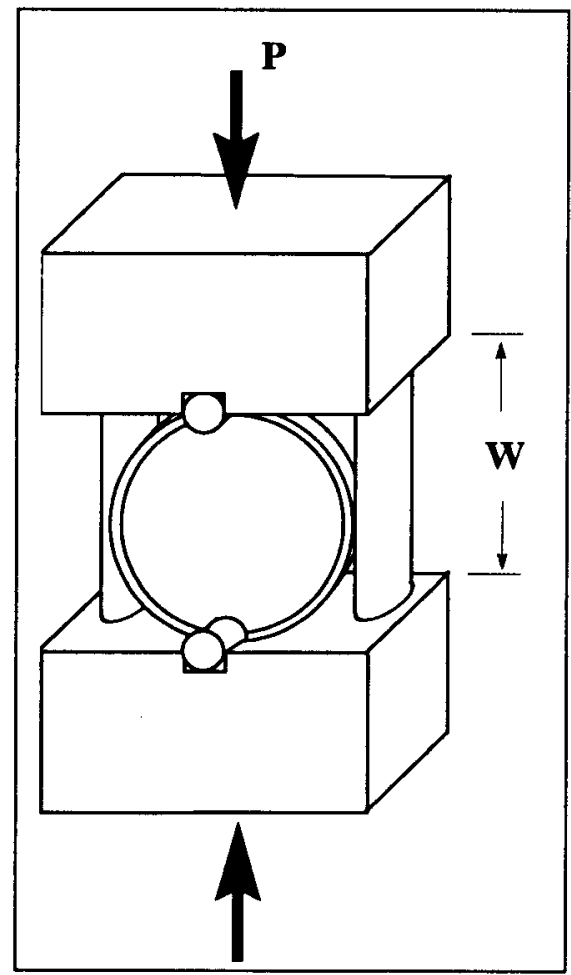


Figure 1. Plot of pressure vs. strain gage readings for AAI-28 S-2 Glass/Epoxy ring.

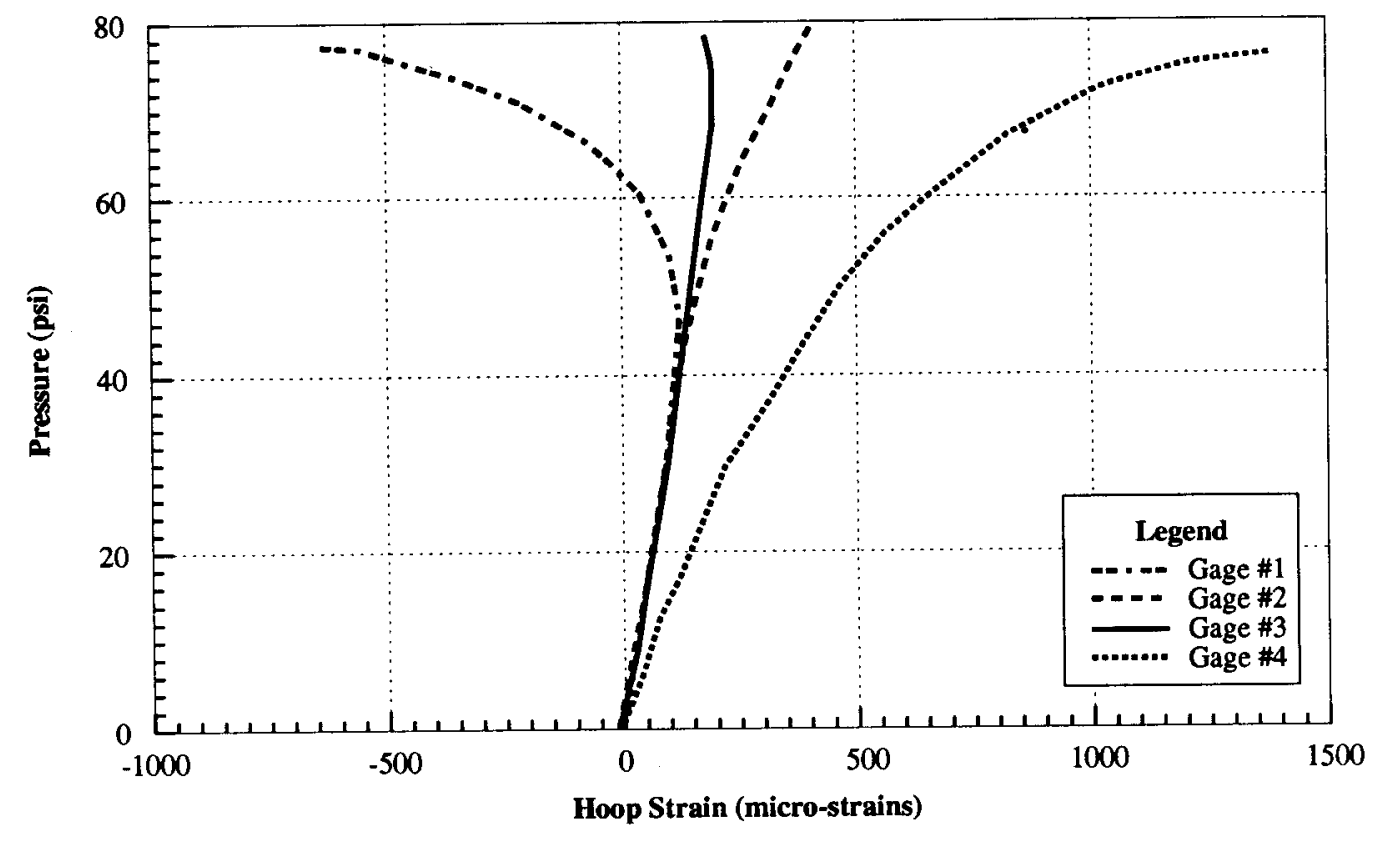

Figure 2. Plot of pressure vs. strain gage readings for ADC-28 AS4/PPS ring.

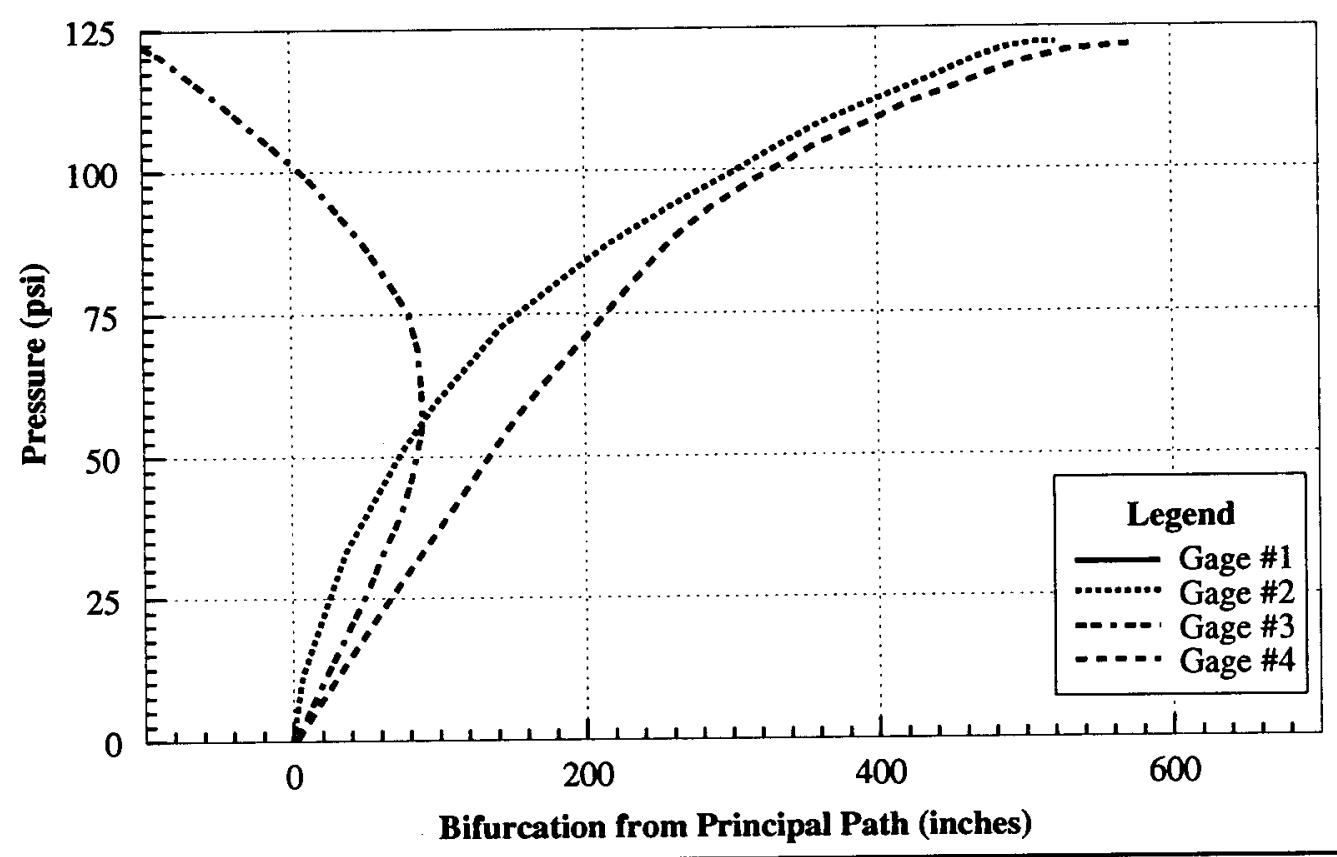




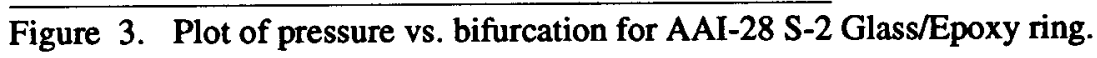

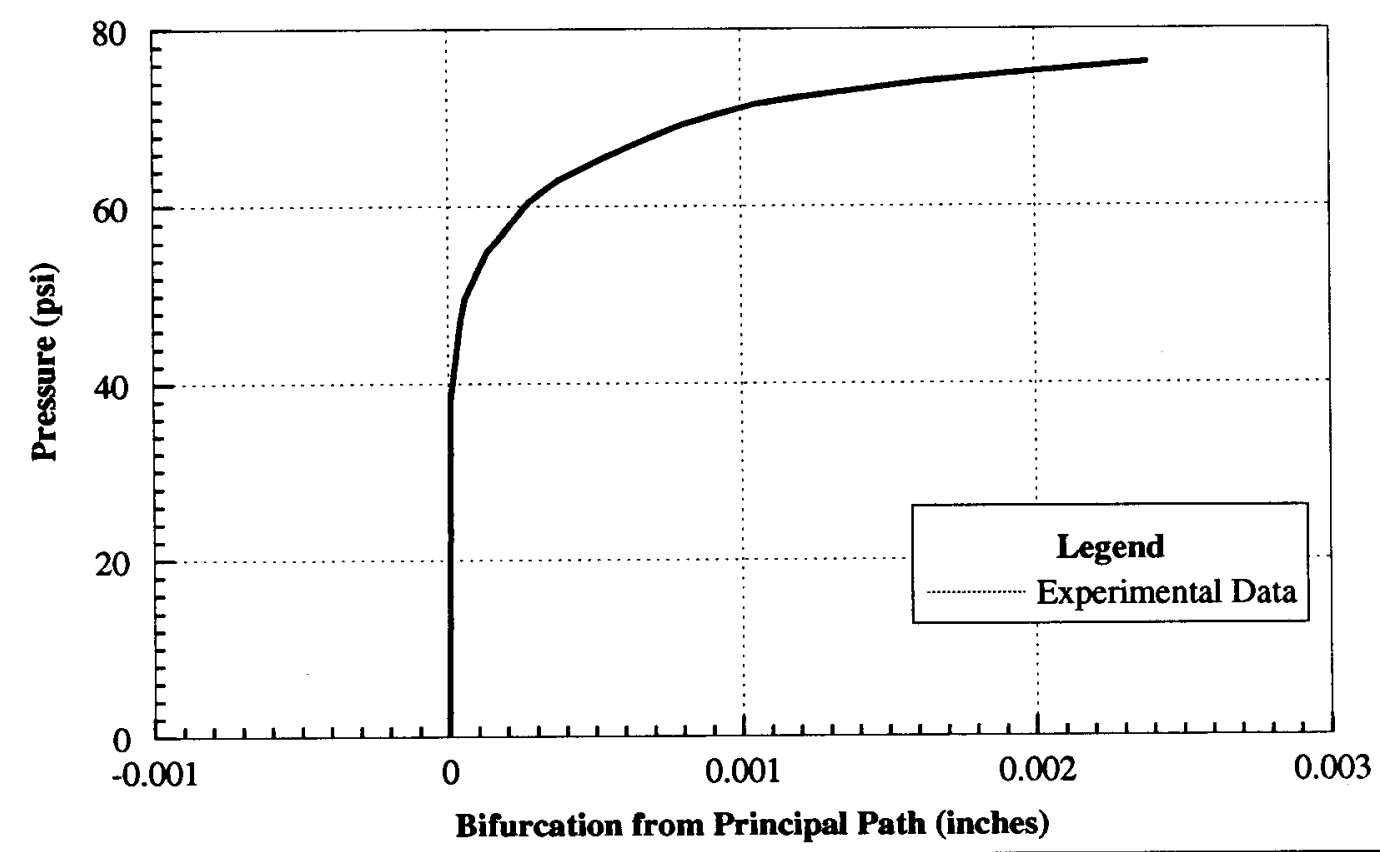

Figure 4. Southwell plot for AAI-28 S-2 Glass/Epoxy ring.

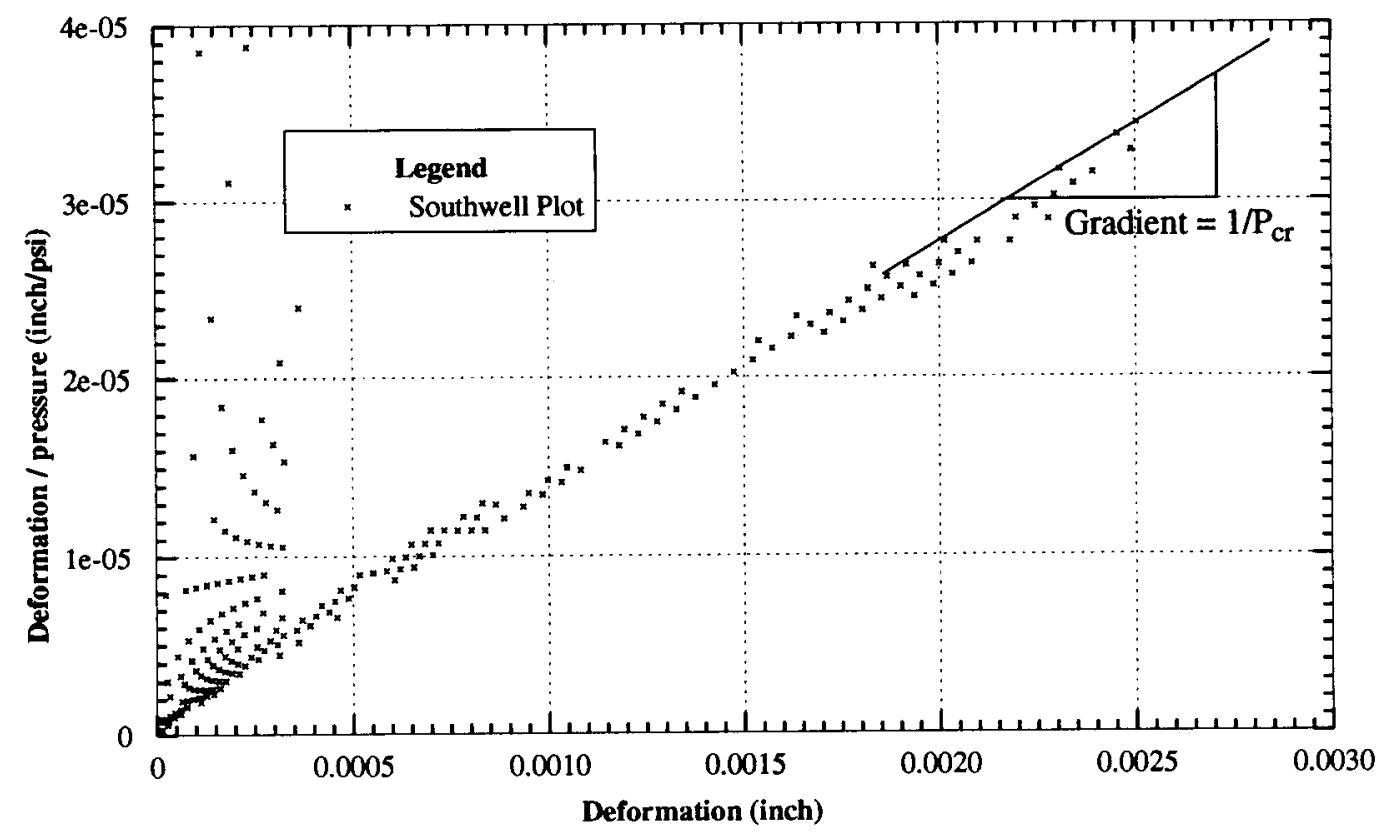


TABLE 1. Buckling Results for S-2 Glass/Epoxy Rings of various thicknesses.

\begin{tabular}{|c|c|c|c|c|}
\hline $\begin{array}{c}\text { S-2 Glass/Epoxy } \\
\text { Ring Specimens }\end{array}$ & $\begin{array}{c}\text { Radius to } \\
\text { Thickness Ratio } \\
(\mathrm{R} / \mathrm{t})\end{array}$ & $\begin{array}{c}\text { Exp. Buckling } \\
\text { Pressure } \\
\text { (strain gages) }\end{array}$ & $\begin{array}{c}\text { Exp. Buckling } \\
\text { Pressure } \\
\text { (Southwell) }\end{array}$ & $\begin{array}{c}\text { Theoretical } \\
\text { Buckling Pressure } \\
\text { (El Naschie) }\end{array}$ \\
\hline AAI-28 & 27.5 & 79.5 & 96.8 & 94.2 \\
\hline AAI-29 & 14.0 & 689. & 762. & 713. \\
\hline AAI-30 & 9.50 & N.A. & 2270. & 5140. \\
\hline AAI-31 & 7.25 & 4910. & 5710. & 9530. \\
\hline AAI-32 & 5.90 & $5015 .^{\mathrm{a}}$ & --- & 15700. \\
\hline AAI-33 & 5.00 & $5021 .^{\mathrm{a}}$ & --- & 2280. \\
\hline
\end{tabular}

a. Buckling not achieved. Design limit of pressure chamber reached.

TABLE 2. Buckling Results for AS4/PPS Rings of various thicknesses.

\begin{tabular}{|c|c|c|c|c|}
\hline $\begin{array}{c}\text { AS4/PPS Ring } \\
\text { Specimens }\end{array}$ & $\begin{array}{c}\text { Radius to Thickness Ratio } \\
(\mathrm{R} / \mathrm{t})\end{array}$ & $\begin{array}{c}\text { Exp. Buckling } \\
\text { Pressure } \\
\text { (strain gages) }\end{array}$ & $\begin{array}{c}\text { Exp. Buckling } \\
\text { Pressure } \\
\text { (Southwell) }\end{array}$ & $\begin{array}{c}\text { Theoretical } \\
\text { Buckling } \\
\text { Pressure (El } \\
\text { Naschie) }\end{array}$ \\
\hline ADC-28 & 27.5 & 150. & 133. & 180. \\
\hline ADC-29 & 14.0 & 1400. & 1300. & 1365. \\
\hline ADC-30 & 9.50 & $400 .^{\mathrm{a}}$ & 3680. & 4370. \\
\hline ADC-31 & 7.25 & $4880^{\mathrm{b}}$ & --- & 9840. \\
\hline ADC-32 & 5.90 & $5030^{\mathrm{b}}$ & --- & 18200. \\
\hline ADC-33 & 5.00 & $5140^{\mathrm{b}}$ & $-\ldots-$. & 30100. \\
\hline
\end{tabular}

a. Approximate as loading was only up to 3800 psi.

b. Buckling not achieved. Design limit of pressure chamber reached. 